$\begin{array}{ll}\text { Abstracta Iranica } & \begin{array}{l}\text { Abstracta Iranica } \\ \text { Revue bibliographique pour le domaine irano-aryen }\end{array} \\ & \text { Volume } 25 \mid \mathbf{2 0 0 4} \\ & \text { Comptes rendus des publications de } \mathbf{2 0 0 2}\end{array}$

\title{
Il natale della luce. Il sada tra Baghdad e Bukhara tra il IX e il XII secolo. Mimesis, Milano, 2002, 379 p.
}

\section{Michele Bernardini}

\section{(2) OpenEdition}

Édition électronique

URL : http://journals.openedition.org/abstractairanica/4460

ISSN : 1961-960X

\section{Éditeur :}

CNRS (UMR 7528 Mondes iraniens et indiens), Éditions de l'IFRI

Édition imprimée

Date de publication : 15 mai 2004

ISSN : 0240-8910

\section{Référence électronique}

Michele Bernardini, « II natale della luce. II sada tra Baghdad e Bukhara tra il IX e il XII secolo. Mimesis, Milano, 2002, 379 p. », Abstracta Iranica [En ligne], Volume 25 | 2004, document 127, mis en ligne le 15 mars 2006, consulté le 25 septembre 2020. URL : http://journals.openedition.org/abstractairanica/ 4460

Ce document a été généré automatiquement le 25 septembre 2020.

Tous droits réservés 


\title{
Il natale della luce. Il sada tra Baghdad e Bukhara tra il IX e il XII secolo. Mimesis, Milano, 2002, $379 \mathrm{p}$.
}

\author{
Michele Bernardini
}

1 Cet ouvrage trace l'histoire de la célébration du sade pendant une période qui va de la fin $\mathrm{du} 9^{\mathrm{e}}$ au $12^{\mathrm{e}} \mathrm{s}$. Dans le premier chapitre, après un excursus critique sur les principaux travaux et sur la typologie des sources utilisées, l'A. mentionne les descriptions historiques des célébrations qui se déroulèrent à l'époque ziyaride et samanide, comme celles de 902-03 pour Mardâvij b. Ziyâr, ou pour Nașr b. Aḥmad Sâmâni (r. 914 - 942-43). Dans ce cadre sont aussi mentionnés deux sades tenus pour Bajkam, le ghulâm turc de Mardâvij b. Ziyâr. Ces premières manifestations du sade provenant des sources arabes et persanes, permettent à l'A. de reconsidérer certaines hypothèses concernant le système selon lequel on fixait la date du sade (le centième jour de l'hiver). L'A. analyse les éléments chrétiens et ceux d'Asie centrale - "le système altaïque" envisagé par Altan Gokalp - en proposant une nouvelle hypothèse "iranique". L'A. retrace ainsi l'occurrence des célébrations du sade aux époques buyide, ghaznavide et seldjoukide en utilisant de nouvelles sources, notamment Muqaddasi et Bayhaqi (ce

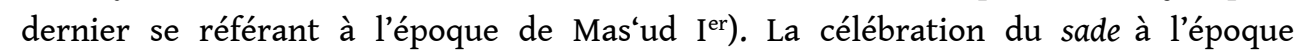
ghaznavide semble attestée une dernière fois au $12^{\mathrm{e}} \mathrm{s}$. à l'époque de Arslanšâh $\mathrm{b}$. Mas'ud III. Quant aux Seldjoukides, l'A. souligne l'importance de la célébration à l'époque de Malikšâh.

2 Le deuxième chapitre est dédié aux modalités des célébrations. Celle d'allumer les feux en brûlant des animaux vivants ainsi que des noix et des amandes représente certes une question intéressante, aussi bien en ce qui concerne un héritage préislamique éventuel qu'une élaboration postérieure pour laquelle l'A. évoque la possibilité d'un rituel laïque. L'A. ne manque pas de souligner la présence dans la littérature poétique de ce thème, attesté parmi d'autres chez Farroxi, 'Asjadi, 'Onșori, Manučehri et Moxtari. Parmi les auteurs arabes, il faut souligner le témoignage d'Aḥmad b. Baššâr, rapporté par Ibn al-Faqih al-Hamadâni, qui paraît être une véritable description d'un 
usage tout à fait répréhensible aux yeux du lettré “étranger”. D’autres sources, telles que al-Ÿuli, soulignent la tradition concernant les cadeaux en décrivant un sade qui se tint à l'époque du ghulâm Bajkam.

3 En guise de conclusion, dans le dernier chapitre du livre, l'A. cherche à saisir les origines incertaines des données fournies par les sources narratives sur le sade islamique. Il note une tendance à mélanger des thèmes différents, comme l'analogie entre le sade et le mehragân le suggère. Ainsi il analyse certaines explications et pseudoétymologies anciennes, notamment celle rapportée par Biruni, Gardizi, Zakariyâ Qazvini et Qalqašandi, qui prétendent dériver le sade du rappel de la célébration du mariage des cent fils de Kay,mart (ou d'Adam et Ève). En revanche, pour Ferdowsi le sade serait la célébration de la victoire de Hošang contre le serpent/dragon noir. D'autres le considèrent une commémo-ration de l'avènement au trône du même Hošang, de la victoire de Zâv (Zâb) fils de Țahmâsp sur Afrâsyâb, ou encore de l'allumage de feux par les survivants du conflit entre Fereydun et Ẓahhâk. Biruni nous informe aussi du fait que le sade est l'œuvre d'Ardašir $\mathrm{I}^{\mathrm{er}}$. Toutes ces indications portent l'A. vers une analyse d'ensemble du sade dans laquelle il trace un cadre de référence complexe pour définir ce mythe de renouvellement qui est lié au solstice d'hiver.

\section{INDEX}

Thèmes : 4.1. Histoire médiévale

nompropre Ferdowsi, Muqaddasi, Bayhaqi, Farroxi, FarroHi, Farrokhi, 'Asjadi, 'Onșori, Manučehri, Moxtari, MoH̦tari, Mokhtari, Aḥmad b. Baššâr, Ibn al-Faqih al-Hamadâni, al-Ÿuli, Biruni, Gardizi, Zakariyâ Qazvini, Qalqašandi

\section{AUTEURS \\ MICHELE BERNARDINI}

Université de Naples 